recommending the consideration of his writings as a moral exercise, challenging ourselves to reflect on the ways in which he might be right.

Janaki Bansal, ST6 Child and Adolescent Psychiatry, Tavistock and Portman NHS Foundation Trust, London, UK; email: janakibansal@nhs.net

1 Benning TB. No such thing as mental illness? Critical reflections on the major ideas and legacy of Thomas Szaz. BJPsych Bull 2016; 40: 292-5.

2 Kendell RE. The myth of mental illness. In Szasz Under Fire: The Psychiatric Abolitionist Faces his Critics (ed JA Schaler). Open Court, 2004.

3 Jones, R. Code of Practice Mental Health Act 1983. In Mental Health Act Manual (11th edn): p. 695. Sweet and Maxwell, 2008.

4 Delgadillo J, Asaria M, Ali S, Gilbody S. On poverty, politics and psychology: the socioeconomic gradient of mental healthcare utilisation and outcomes. Br J Psychiatry 2016; 209: 429-30.

5 Loring B, Robertson A. Obesity and inequities. Guidance for addressing inequities in overweight and obesity. World Health Organization, 2014

doi: $10.1192 / p b .41 .2 .120 a$

\section{Understanding challenges around implementation of specialist service recommendations for obsessive-compulsive disorder}

Harris \& Drummond's ${ }^{1}$ recent paper exploring the rate of adherence to recommendations made by their specialist obsessive-compulsive disorder (OCD) service is an important reminder of the need for tertiary and specialist services to liaise with clinicians in secondary care.

Their study found that almost $40 \%$ of their medicationrelated recommendations and $20 \%$ of the recommendations involving community mental health teams had not been implemented prior to admission to their specialised unit. In addition, 6 months after discharge around 25\% of recommendations had yet to be implemented. This suggests that many patients may not be receiving potentially beneficial treatments, thus prolonging the detrimental impact that $O C D$ has on the individual and their family.

Understanding the issues affecting implementation is important since it is neither possible nor appropriate for specialist services to mandate recommendations to be followed at a local level. Treatment recommendations should be a negotiation between the local treatment team and the patient. It is difficult to be critical of limited implementation without understanding the factors affecting low implementation rates.

In our nationally funded specialist OCD service we are developing an outreach model, designed to enhance functional links with local services. This will target people who have been referred for consideration for the intensive treatment programme for $O C D$, but have not completed the required pharmacological or psychological treatment trials during their contact with local services. The specialist service's consultant psychiatrist will liaise with the local area consultant to discuss pharmacological options and will offer ongoing troubleshooting (via phone or email) regarding implementation. The specialist psychological therapy staff will support local psychology and nursing staff to provide behavioural treatment and will offer up to 10 hours of individual, patient-focused education and support to the local team. This will cover areas such as knowledge and understanding of OCD, assessment for cognitive-behavioural therapy, formulation, hierarchy building, treatment planning and, importantly, working with families. This time-limited, integrated working model is designed to help both services to develop a shared understanding of the diagnostic formulation, treatment recommendations and challenges to implementation. It also means that the specialist service has a much better knowledge of the patient should they require more intensive treatment subsequently.

By front-loading specialist input at an earlier stage in the pathway, patients will be supported to progress through treatment options more rapidly, and local teams will have the opportunity to develop skills and confidence in managing patients with severe and treatment-refractory OCD.

To better understand barriers to implementation we are in the process of reviewing all patients with OCD seen for assessment and/or treatment by our service since 2010. As part of this process we will be meeting with local clinicians to discuss both the perceived utility and the impact of our treatment recommendations, as well as any difficulties that were encountered during implementation.

Ultimately, we suspect that even if treatment recommendations have been fully implemented, many people will continue to struggle with disabling OCD. Indeed, even after intensive, specialised treatment within their own unit, Harris \& Drummond noted that $70 \%$ of patients were either 'nonresponders' or gained only partial benefit. Although disappointing, this is consistent with other published data indicating that full response or asymptomatic states in patients with a severe burden of symptoms are rare. ${ }^{2-4}$ This raises the important question of how to optimise treatment for people with OCD within both secondary and tertiary services. There is a clear need to improve our ability to identify earlier those individuals who may not benefit from standard treatments, and to explore and improve treatment options for this relatively large population with OCD that remains refractory to both state-of-the-art pharmacotherapy and psychological therapy. This is, arguably, the biggest single challenge facing both specialist services and secondary care teams.

Karen J. Walker, Senior Mental Health Nurse Psychotherapist, email: karenwalker3@nhs.net and David M. B. Christmas, Consultant Psychiatrist, Advanced Interventions Service, Ninewells Hospital and Medical School, Dundee, UK.

K.J.M. and D.M.B.C. both work within a nationally funded NHS-based specialist service providing assessment for and intensive treatment of people with OCD.

1 Harris PM, Drummond LM. Compliance of community teams with specialist service recommendations for obsessive-compulsive and body dysmorphic disorders. BJPsych Bull 2016; 40: 245-8.

2 Veale D, Naismith I, Miles S, Childs G, Ball J, Muccio F, et al Outcome of intensive cognitive-behaviour therapy in a residential setting for people with severe obsessive-compulsive disorder: a large open case series. Behav Cognit Psychother 2016; 44: 331-46.

3 Boschen MJ, Drummond LM, Pillay A. Treatment of severe, treatmentrefractory obsessive-compulsive disorder: a study of in-patient and community treatment. CNS Spectrums 2008; 13: 1056-65.

4 Björgvinsson T, Hart AJ, Wetterneck C, Barrera TL, Chasson GS, Powel DM, et al. Outcomes of specialised residential treatment for adults with obsessive-compulsive disorder. J Psychiatr Practice 2013; 19: 429-37.

doi: $10.1192 / p b .41 .2 .121$ 